\title{
On the Potential of Various Approaches tothe Semantics of Novel English Compounds
}

\author{
YuliaVorobeva, PhD \\ Department of English and Literature \\ College of Arts \\ University of Bahrain \\ Kingdom of Bahrain
}

\begin{abstract}
The purpose of this research is to delineatehow various linguistic approaches act while interpreting the meaning of new English compounds. The research sheds light on some of the contemporary compounding theories, such as reductionist, transformational, slot-filler and pragmatic theories as well as onomasiological approach (i.e. cognitive onomasiology)that elucidate how meaning is activated in compounds.The research concludesthat meaning interpretation of new English compounds does not only depend on their onomasiological pattern which determines the relationship between its constituents but also various types of context including extra-linguistic context as well as a cognitive principle of relevance plays a pivotal role in this process.
\end{abstract}

Keywords: Compounding theories, Inference, Pragmatics, Context, Relevance

The purpose of this article does not imply to discuss all existing theories that are applied for the analysis of compounds in contemporary linguistics. On the contrary, it will demonstrate some approaches to the analysis of new compounds using the examples from contemporary English to testify how some of these approaches are activated in interpretingthe meaning of new compound words as well as compare their pros and cons.

One of the straightforward views towards analysis of existing compounding theories was expressed by Søgaard(2005) who differentiates between four of them. They are: reductionist theories, transformational theories, slot-filler theories and pragmatic compound theories. To this list one can add also cognitive-semantic approachthat is applied for the analysis of compounds including conceptual blending analysis, generative lexicon methodand onomasiological approach. Let's investigate some of them in brief.

\section{Reductionist theories}

Hatcher (1960) proposed a four way taxonomy towards analysis of English noun compounds. In a nutshell, it was suggested that determinative non-appositional noun compounds be reclassified. The classification originally belongs to Jesperson and Mätzerwho divided such compounds into 8 groups which Hatcher shrankinto 4 'relational categories' (the term belongs to Hatcher). These four relational categories consist of two pairs each: the static(A) and (B)and the dynamic $\mathrm{A} \rightarrow \mathrm{B}$ and $\mathrm{B} \leftarrow \mathrm{A}$. (A) denotes something that is implied in $\mathrm{B}$ and it can be expanded, while $\mathrm{B}$ is something that is related to A. In other words, A is included in B and Bis included in A. Consider the examples suggested by Hatcher: orange seed is (B)and seed orange is (A).The dynamic relationships can be traced in the examples with cane $\operatorname{sugar}(\mathrm{A} \rightarrow \mathrm{B})$ and sugar cane $(\mathrm{B} \leftarrow \mathrm{A})$ (Hatcher, 1960). The main criticism of such approach is related to the fact that it reveals finite set of simple bonds between compound constituents. According to Søgaard (2005) such conclusion is arguable as there are unlimited combinations in interpreting compounds. This thesis was convincingly introduced by Bauer (2013) who believes that the number of meaning relationships between compound constituents is 'far from exhaustive'. He considers that any compound consisting of two elements can presented as 'AB' structure. Below you can see a meaning relationship list with the examples. The list is not full though (see the full version in Bauer, 2013).

\section{Meaning relationship list Examples}

A CAUSES B

A IS CAUSED BY B

A IS PREVENTED BY B

B RESEMBLES A

A IS AT PLACE B heat rash, shell shock

flu virus

tetanus jab

frogman, hairpin bend

ant heap, bookshop 
Bauer further argues that there is no information in the compound itself that explains how to interpret it. He stresses that all efforts to propose a complete list of meaning relationships in compounds have not succeeded so far as it can be a challenging task to analyze meaning relationship between constituents in some compounds such as domino theory, milk tooth or spaghetti western.

One more point of view that goes to opposition with the reductionist theories on interpretation of compound meaning was expressed by Hansen (2003) who claims that meaning of a compound depends on: a) the meaning of each part of the constituent; b) the semantic relationship between the constituents. Relationship that exists between the compound constituents can be classified as determinant-determinatum relations. The example with beet-sugar, grape-sugar and cane-sugar stress the idea that the second part of the compound mostly plays the role of the determinatum while the first element is the determinant. Therefore, in the above examples a certain type of sugar is subcategorized out of the whole class of sugar. Nevertheless, Hansen (2003) manifests that determinant-determinatum relation does not seem to provide a full understanding of the compound meaning. The important role of logico-semantic relation between the elements of the compound is stressed as well as topicalization and extra semantic components. Logico-semantic model can be discussed in terms of 'predication analysis' which examines predicate types and specifies the 'nominal role types' identified between the compound constituents. He differentiates between three basic types: Statal, Processual and Actional. Topicalization is the choice of the determinant and the determinatum that is performed whilst organizing predicate and role types in the compound constituents. Finally, extra semantic components such as [+PROFESSIONAL], [+HABITUAL] and [+PURPOSE])regularly take place as expected elements in the meaning interpretation of the compounds. Consider the suggested analysis of the compound playroom(Hansen, 2003):Actional ${ }^{\mathrm{dt}}$ + Locative $^{\mathrm{dm}}$ [+PURPOSE].

\section{Transformational theories}

One of the representatives of this approach is Lees (1960) who advocated the idea of producing compounds from the kernel sentences by following the order of transformations. One of the obstacles of that approach is the numerous number of grammar forms, which as Štekauer (2005) notices leads to 'multiplicity of meanings' or meaning ambiguity. Compare the examples discussed inŠtekauer (2005): 'snake poison' can be interpreted as 'poison from snake' or 'poison for snake'. Another example of a 'garbage man' is mentioned in Søgaard who comments that a 'garbage man' does not necessarily mean 'a man who carries garbage' (Søgaard, 2005). Lees's approach was criticized by Dokulil, Marchand(cited in Štekauer, 2005) mainly due to the fact that his theory was unable to present accurate criteria in meaning interpretation of compounds.

\section{Slot-filler theories}

One more type among contemporary theories can be called slot-filler theories. The representatives of this approach are Cohen \& Murphy (1984). They propose to interpret complex compounds such as $\mathrm{N}+\mathrm{N}$ and Adj+N using knowledge representation model of prototype theory. They refer to the interpreter's world knowledge in analyzing parts of the compound as in case the interpreter lacks it, it would be hard for him to understand the relationship between its parts. Cohen and Murphy consider that their slot filling theory demonstrates the possibility of filling a slot in the head's concept schema at the same time ascribing a modifying characteristic to it.As an example, they analyze the ambiguity of some noun phrases such as finger cupwhich might be interpreted in various ways, including a cup which has a shape of a finger or a cup that is used for washing fingers. They claim that in order to understand the meaning of such compounds the two concepts which are expressed in every part of the compound should be 'knowledge -dependent' (Cohen \& Murphy,1984) as well as related to the knowledge of the context. The context helps to initiate certain properties of the head noun over its other components which triggers in its turn a 'matching process' (the term belongs to Cohen \& Murphy,1984) with other properties of the compound. Štekauer (2005) considers that it is not easy to apply this strategy while analyzing 'complex concepts'. This conclusion is underpinned by A. Søgaard who assumes that these theories demonstrate some weaknesses as constituents of the endocentric compounds might present more than one feature. At the same time he concludes that endocentric compounding is more productive than exocentric and this should be taken into account as well (2005).

\section{E. Wisniewski two-process model}

Wisniewski (1997) suggested a two-process model for analyzing compounds using context-free word interpretation strategies. He differentiated between two main interpretation strategies, the relation linking and property mappingwhich occurs from one part of the compound to another. According to E. Wisniewskirelation-linking interpretation is associated with generating a certain scenario which employs compound parts. He inspects the example of a 'truck soap' where 'truck' is ascribed to the recipient role which explains a washing procedure and 'soap' - to the instrumental role, something which is used to perform washing. 
Due to the scenarios activation the modifier and the head noun are capable to perform various roles in an 'action, state, or event'. Such vision approached relation-linking interpretations to the schematic conceptual representation. Property interpretations underline the idea of a distinction between a head and a modifier as in order to evaluate the property interpretation there appears indispensable to set a novel concept that is non-identical to the head noun and is related to the modifier at the same time. Wisniewski distinguishes two processes which are characteristic for property interpretations. They are: comparison and construction processes. The first one regulates similarities and distinctions between the head and the modifier while analyzing each of them. The second presents the result of the comparison process which produces new information. P. Stekauer (2005) observes the idea of similarity of concepts expressed by E. Wisniewski and draws a conclusion that semantic compatibility of all semes expressed in two active constituents is characteristic to all novel and context-free expressions which might have different Predictability Rates (the term is used by Štekauer (2005: p. 31)).

\section{Onomasiological approach to the meaning interpretation in compounds}

Dokulil (1997), cited inŠtekauer (2005), is one of the pioneers in the onomasilogical theory of word formation analysis. He introduced the notion of onomasiological category which is closely related to the idea that a naming process is activated in the human mind. He also observed the role of meaning predictability for word-formation motivated word that goes within the framework of onomasilogical approach. While analyzing predictability of meaning in naming units Dokulil stressed the idea of structural meaning where various relations between common word formation meaning and particular lexical meaning take place (e.g. teacher, where word formation type of a person performing an action is clear). It is indisputable that predictability of such words is obvious. In contrast, in some compound nouns the division between lexical meaning and word formation meaning can be seen, e.g. cabinet-maker is a person who makes all types of furniture but not only cabinets. Dokulil summarized that word formation meaning is a part of the language system and lexical meaning is related to the norm. But the norm might not include all characteristics that are present in the system.

Štekauer is convinced that there is a strong connection between onomasiological, word formation and morphological types as the interpretation of meaning predictability is heavily dependent on the structural pattern which is used in the formation process (2005). In his further research of naming processes Stekauer differentiates between five onomasiological types where he analyzes types of onomasiological (semantic) structures that are used in the naming process. He proposes three basic constituents of the onomasiological structure: determining constituent of the mark determined constituents of the mark - onomasiological base. Determined constituent denotes the concept of action which can be analyzed in its various forms: process, action proper and state. Onomasiological base encompasses the entire class to which the object is classified. There are five onomasiological types which are singled out byŠtekauer. Onomasiological type I presents all three constituents: onomasiological base, the determined and determining constituents (language teacher, brain-storming, air hostess, etc). Onomasiological type II contains only the determined constituent (lock pin). This type can be expanded to Onomasiological type I (teacher can be expanded to language teacher, dance teacher, private teacher). Onomasiological type III includes the determined constituent that cannot be expanded (policeman, alpinist, honey bee). This type 'triggers matching process that starts at the level of prototypical semes' (Štekauer, 2005: 76). Onomasiological type IV does not possess determining and determined components. It has two parts: the onomasiological base and the onomasiological mark, for example blue-eyed can be decomposed into the base -ed and the mark blue eye. Onomasiological type $\mathrm{V}$ deals with onomasiologicalrecategorization which is conventionally referred to conversion. For instance, databank is related to SUBSTANCE, when the process of recategorization starts it turns into ACTION.

\subsection{Cognitive onomasiology}

It is important to notice that onomasiology within time was impacted by cognitive approach in linguistics and as a result it gave birth to cognitive onomasiology. Grondelaers and Geeraerts (2003) shed light on the basic principles of cognitive onomasilogy which deals with the concepts that can be used for naming. At the same time, they stress the idea of 'pragmatic conception of onomasiology' which specifies choices that are performed by the referent in the process of naming. Blank (2003) considers cognitive onomasiology through the prism of diachrony. He is convinced that cognitive onomasiology can help to comprehend processes of conceptualization in languages occurring over time. He stresses that these processes have become blurred and need reconsideration. Acoording to Blank cognitive onomasiology 'can procure us a deeper insight into the way our mind works' (2003:44). It is crucial to notice that 'universal conceptualization' (the term is used by Blank) is not possible in every language, on the contrary it occurs differently in every society. Taking into account the latest changes in onomasiology and its overlap with cognition it is conceivable to state that conceptualization influences the meaning predictability in word formation processes in general and compounds in particular. 


\section{Pragmatic approach to the meaning of compounds}

Kiefer claims that there is not much information related to pragmatics of compounds. To his mind, morphopragmatics studies how pragmatics affects 'ad hoc compounds' and lexical compounds are not included in the field of morphopragmatics (Kiefer, 2001). Nevertheless, Bauer and Meibauersuggest the idea which accounts the indispensability of pragmatic principles in the interpretation of the meaning of compounds as compound structure (AB) demonstrates only superficial knowledge which is not enough for its adequate meaning interpretation. Bauer clarifies that in order to process the relationship between compound constituents, the following knowledge is required: 1. Knowledge of the world; 2. Beliefs about the structure of the world; 3. Knowledge of the artefacts connected with the society and 4. Knowledge of the qualities associated with a particular entity (Bauer, 1979; Maibauer, 2014). Furthermore, Bauer suggests including pragmatic information in the lexicon which is argued by Meibauer (2014) who proposesthe mechanism of pragmatic inferencing which can help to avoid any vagueness in the meaning interpretation and can only be activated in the context.

Another pivotal factor that should be taken into consideration while analyzing meaning of compounds is related with the relevance principle. Schmid (2011) underpins the idea that compounds have pragmatic function which makes communicators' speech be relevant to a specific context and at the same time compound constituents should possess relevance which should be able to connect them with other mental spaces that the constituents refer to. This explanation stems from the theory of relevance introduced by Sperber and Wilson (2002) which gives invaluable explanation to the theory of meaning stressing the role of intentions, decoding and encoding processes, inference as well as cognitive effects in the process of communication. The fundamental conclusion of the relevance theory is associated with its cognitive nature. Moreover, Sperber and Wilson define relevance as the characteristic of expressions and other properties that are associated with cognition which was clearly put in their first principle: 'The cognitive principle of relevance: Human cognition tends to be geared to the maximization of relevance'. Sperber and Wilson (1986, 1987)claim that cognitive principle of relevance deals with a basic premise related to human cognition and it justifies their attitude towards the communication process.

Finally, it is worth to mention the role of context in the interpretation of meaning in compounds. Meyer (1993) analyzed the meaning of novel noun-noun compounds in German and concluded that there is a number of factors that influence their adequate interpretation. To these factors Meyer assignscontextual information and conceptual knowledge. Lexical items are related to concepts where the process of mapping between items in the concepts does not follow the same pattern. In order to designate the relevant conceptual information in the compound it is necessary to refer to the contextual support. Analysis of novel noun-noun compounds in English does not seem to contradict this judgement.

Contextual interpretationmight assist in reducing the incongruity between how the word is decoded in the context and its 'stored semantic representation' (Taylor, 2012). In this case contextual interpretation would be associated with a choice of required saved meanings. Furthermore, contextual interpretation of the meaning does not necessarily correspond with any meanings that are saved. Various meaning interpretations are offered only when there is no possibility to extract information from the context or the surrounding environment. On the other hand, A. Søgaard considers that pragmatic approach to the meaning comprehension in compounds might lead to wrong meaning interpretations due to the lack of direct relationships between compound members pointing at the absence of generalization. He concludes that all these obstacles create constant opaqueness in meaning interpretation for pragmatic theories. As an example,the compound stone lion which can present limited interpretations for the speaker is discussed (Søgaard, 2005). To sum up, Søgaard is convinced that context in pragmatic theories is a primary component which is activated by means of combination of features in the so called ' $\mathrm{k}$-structure' and discourse structure.

\subsection{Context and its types}

In the field of pragmatics several types of context are distinguishedwhich could be applied in the meaning interpretation of compounds (Fetzer, 2002, King \&Stanley, 2005). Let's consider them in short. Fetzer $(2002,2004)$ differentiates between three types of context: linguistic context, cognitive context and a social context. Linguistic context is narrowed by various types of genre and is marked by limitation. Furthermore, language consists of 'linguistic constructions' (the term is offered by A. Fetzer) which are surrounded by other neighboring linguistic constructions and thus are able to produce a clause, a sentence or a text. Linguistic construction like speech acts compose a text. The creation and decoding of the linguistic constructions is always limited by grammatical rules, while reading of speech acts depends on appropriateness. Cognitive context implies the idea of inference and different types of arguments. Mental representations, propositions, contextual and factual deductions are supposed to be essential components of the cognitive context. Due to the fact that cognitive deductions are ascribed to an interlocutor and to the process of communication, they express the idea on joint cognitive space. 
Consequently, cognitive context is presented not only by representations but also meta-representations (Fetzer, 2011) as well as it poses the difference between figure and ground, and frame and framing in the gestalt-psychological approach. Finally, social context refers to a communicative interchange. Language users, physical setting, such as time and locus as well as institutional/non-institutional domains are supposed to be components of social context.

At the same timea context might affect communication. King and Stanley (2005) distinguish two conditions when it is possible. The first one takes place when context influences the semantic core of the sentence through the presence of reference-oriented sentence content. The second occurs when context determines communication despite the semantic content of the utterance. Here, they emphasize the significant role of extra-linguistic context which impacts the meaning of some language utterances. Analyzing further the function of the context, they single out the characteristic called 'pragmatic effect' which can be represented by two types: a weak type and a strong one. A weak pragmatic effect influences understanding of a language expression depending on the meaning of the language expression. A strong pragmatic effect is associated with the 'contextual effect' that a language expression produces.

\section{Analysis of some new English compounds}

In this part the meaning of some new compounds that were chosen by random from The Oxford Dictionary of New Words is analyzed. The analysis testifies that onomasiological and pragmatic approaches are mostly involved while processing their meanings. Onomasiological aspect suggests the existence of onomasiologocal types where semantic components are mapped with 'a conceptual structure in accordance with the onomasiological model' (Štekauer, 2005). Meaning predictability in the mentioned below compounds is connected, on the one hand with an onomasiological type and, on the other - is related with extra-linguistic reality. Pragmatic approach deals here with knowledge of certain social scenarios and activation of contextual knowledge. The relationship between compound components is presented by conceptual categories such as SUBSTANCE, ACTION, QUALITY etc. The other approaches such as reductionist and transformationaldo not seem to function here as they arenot capable to suggest an adequate meaning interpretation of compounds. Regarding a slot-filler theory, it is not employed in full in the meaning interpretation in compounds from the point that it confirms the existence of various mental categories, i.e. concepts, frames which allow to fill in the slots in the mental schemata but fail to explain the meaning due to the lack of context (see the example with finger сир). Thus, meaning interpretation of concepts in compounds certainly alludes to the existence of relationships between mental concepts and a proper choice of certain conceptual features which is performed by the interlocutor at the moment of communication. The examples below require extra-linguistic knowledge for their meaning interpretation as well as relevant contextual information and thus they seem to fit onomasiological type III.

1. Cardboard city. [This compound means an area of a large town where homeless people congregate at night under makeshift shelters made from discarded cardboard boxes and other packing materials (NOD)]. Compound constituents produce meaning ambiguity, as cardboard city does not only imply the idea of materials from which the city is built. They do not contain any information that these cities are actually places for living. The relevant background knowledge allows to infer additional information such as 'cities' that are usually inhabited and 'built' by people who do not have permanent homes. The ambiguity in the compound is caused by the possibility of various contexts as well where this compound can be used, i.e. cardboard city might be a part of the task/project that students must create while studying city design or it can be also a cardboard city model exhibition. Formal AB relationship structure of the compound fails to explain the meaning suggested in the dictionary. Extra-linguistic factorstriggeradequate meaning interpretation where new prototypical semes,such as live and makeoccur. The compound might be presented in the following way:

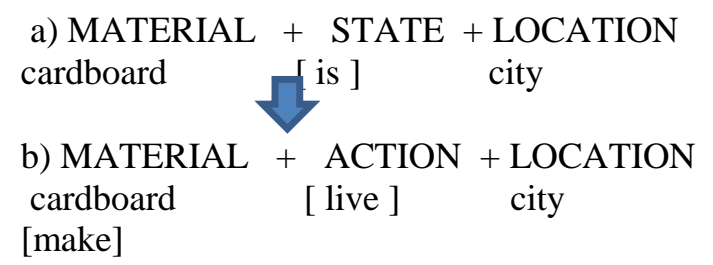

2. Crop circle. [This compound means an area of standing crops which has been inexplicably flattened, apparently by a swirling, vortex-like movement (NOD)]. The compound constituents can be interpreted as a crop that grows in the shape of the circle. The missing part in the interpreting of the compound deals with the idea that the crop looks unusual as it is not standing but flat inside the circle due to inexplicable reasons. As a result, new prototypical semes 'flat' and 'odd' can be identified by referring toextra linguistic realityand required context.The compound can be presented as having the following structure: 


\begin{tabular}{|c|c|c|}
\hline $\begin{array}{l}\text { a) PLANT } \\
\text { crop }\end{array}$ & $\begin{array}{l}+ \text { STATE } \\
\text { [looks like] }\end{array}$ & $\begin{array}{l}+ \text { SHAPE } \\
\text { circle }\end{array}$ \\
\hline $\begin{array}{l}\text { PLANT } \\
\text { rop } \\
\text { [odd] }\end{array}$ & $\begin{array}{l}\text { + QUALITY } \\
\text { [flat] }\end{array}$ & $\begin{array}{l}+ \text { SHAPE } \\
\text { circle }\end{array}$ \\
\hline
\end{tabular}

3.Expert system. [This compound means a computer system using software which stores and applies the knowledge of experts in a particular field, so that a person using the system can draw upon that expertise to make decisions, inferences, etc. (NOD)]. The knowledge of a particular contextis needed to interpret the compound, i.e. the field of artificial intelligence and computer technologies. Another possible interpretation of the compound can be extended to any system (not necessarily a computer software) that is able to consult somebody on something. Reference to extralinguistic knowledge explainsthat storing and applying information as well as allusion to the person who uses all this data are preferred over other possible meanings in its interpretation and new prototypical semes such as 'store knowledge' and 'apply knowledge' can be singled out. The structure of it can look like as follows:

a) QUALITY + STATE + STRUCTURE

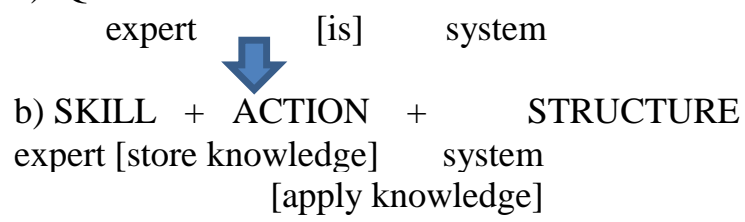

4. Hot button. [This compound means a central issue, concern, or characteristic that motivates people to make a particular choice (among consumer goods, political candidates, social structures, etc. (NOD)]. Compound constituents fail to explain the actual meaning as this Adj $+\mathrm{N}$ compound is metaphorical. Obviously the idea of ' $h i g h$ temperature' is not used any more as 'hot' is related to something important, central or characteristic here. The second constituent 'button' alludes to the expression 'push someone's buttons' which inderlines the idea of 'provoking a reaction in someone'. The metaphorical nature of the compound totally changes the meaning of each constitute and preserves it in a new way. The semantic shift that is observable in this compound goes from the characteristic applied for measuring a temperature into the sphere of human emotions and can be interpreted as something that provokes and causes emotions. New prototypical semes such as 'central', 'provoking', 'influential', and 'emotional' can be established.The compound might have the following structure:

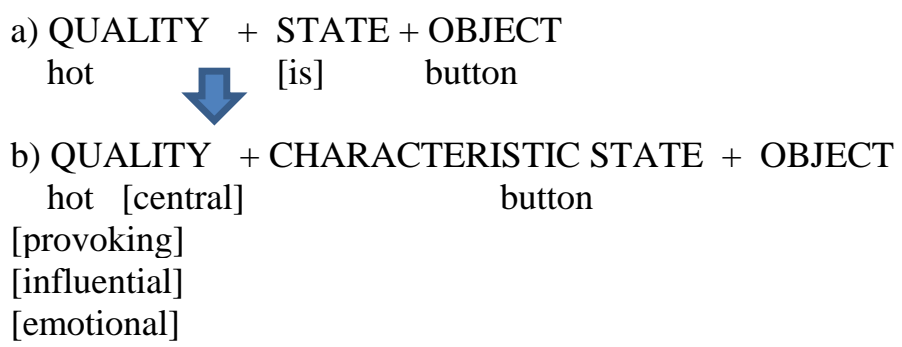

5. Bottle bank. [This compound means a collection point to which empty bottles and other glass containers can be taken for recycling, (NOD)]. The meaning of the compound constituents does not imply that containers are collected and taken further for recycling as well as not only bottles are collected but rather other glass containers. The metonymical interpretation of this compound might go apart with a similar compound blood bank where blood and plasma are stored and not recycled. The meaning of the word bankpresents only a certain feature of it (a deposit place) which is inherited by the compound.New prototypical semes such as 'collect' and 'recycle' can be identified. The compound might have the following structure:
a) MATERIAL + STATE + PLACE bottle [is ] bank
b) MATERIAL + ACTION + PLACE bottle [collect ] bank [recycle] 


\section{Conclusion}

The observation of mentioned above theories showcase that for the analysis of compound meaning a combination of certain theories should be taken into consideration, in particular onomasiological, slot-filler, and pragmatic approaches. All of them seem to be activated to some extent. Elaborate analysis of morphological structure expressed by Štekauer allows to single out compound types and determine theironomasiological structure which in its turn helps to 'predict' a compound meaning by identifying basic prototypical semes.Pragmatic approach mainly deals here with the theory of relevance which is closely related with cognitive effects and a crucial role of context.According to Sperber and Wilson (1998) cognitive effects can be understood in case knowledge about something goes with the context or some present assumptions which can be modified, i.e. reinforced or even cancelled in order to produce a certain 'contextual implication'. They argue that 'The greater the cognitive effects, the greater the relevance will be' (1998:8).Besides, the role ofvarious types of context, such as cognitive and social is influential in compound meaning interpretation. Reductionist and transformational approaches do not tend to be effective as they cannot explain the mechanism of meaning processing paying attention to the formal relationship between compound constituents. Slotfiller and two-process model approaches are partially applicable in analysis of the compound meaningmainly due to the fact that humans conceptualize and categorize the realityand linguistic data is stored as thecomplex mental schemata. Two-process model cannot be fully activated as well because it stresses context-free interpretation of compounds which objects to the suggested analysis. Table 1 below demonstrates the validity level of discussed approaches to the analysis of new compounds.

Table 1. Summary of linguistic approaches towards new compounds

\begin{tabular}{|l|l|l|l|l|l|l|}
\hline $\begin{array}{l}\text { Compound } \\
\text { example }\end{array}$ & $\begin{array}{l}\text { Reductionist } \\
\text { approach }\end{array}$ & $\begin{array}{l}\text { Transformational } \\
\text { approach }\end{array}$ & $\begin{array}{l}\text { Slot-filler } \\
\text { approach }\end{array}$ & $\begin{array}{l}\text { Two-process } \\
\text { model approach }\end{array}$ & $\begin{array}{l}\text { Onomasiological } \\
\text { approach }\end{array}$ & $\begin{array}{l}\text { Pragmatic } \\
\text { approach }\end{array}$ \\
\hline $\begin{array}{l}\text { 1.cardboard } \\
\text { city }\end{array}$ & not valid & not valid & $\begin{array}{l}\text { partial } \\
\text { activation }\end{array}$ & $\begin{array}{l}\text { partial } \\
\text { activation }\end{array}$ & valid & valid \\
\hline 2.crop circle & not valid & not valid & $\begin{array}{l}\text { partial } \\
\text { activation }\end{array}$ & $\begin{array}{l}\text { partial } \\
\text { activation }\end{array}$ & valid & valid \\
\hline $\begin{array}{l}\text { 3.expert } \\
\text { system }\end{array}$ & not valid & not valid & $\begin{array}{l}\text { partial } \\
\text { activation }\end{array}$ & $\begin{array}{l}\text { partial } \\
\text { activation }\end{array}$ & valid & valid \\
\hline 4.hot button & not valid & not valid & $\begin{array}{l}\text { partial } \\
\text { activation }\end{array}$ & $\begin{array}{l}\text { partial } \\
\text { activation }\end{array}$ & valid & valid \\
\hline 5.bottle bank & not valid & not valid & $\begin{array}{l}\text { partial } \\
\text { activation }\end{array}$ & $\begin{array}{l}\text { partial } \\
\text { activation }\end{array}$ & valid & valid \\
\hline
\end{tabular}

\section{References}

Bauer, L. (1979). On the Need for Pragmatics in the Study of Nominal Compounding. Journal of Pragmatics. No.3, pp. 45-50.

Bauer, L. (2013). Language Workbooks: Vocabulary (1). Florence, US: Routledge.

Blank, A. (2003). Words and Concepts in Time. Towards Diachronic Cognitive Onomasiology. In: Eckardt, R., Heusinger, K., Schwarze, C. Words in Time. Diachronic Semantics from Different Points of View(pp.37-66). Berlin/New York: De Gruyter Mouton.

Cohen, B. \& Murphy, G.L. (1984). Models of Concepts. Cognitive Science. № 8, Issue 1, p. 27-58.

Fetzer, A. (2011). Pragmatics as a Linguistic Concept. In: Bublitz, W. \&Norrick, N.R. (ed.) Foundations of Pragmatics( pp.23-51). Berlin/Boston: De Gruyter Mouton.

Fauconnier, G. \& Turner, M. (2002). The way we think. Conceptual thinking and the mind's hidden complexities. New York: Basic Books.

Grondelaers, S. \&Geeraerts, D. (2003). Towards a Pragmatic Model of Cognitive Onomasiology. In: Dirven, R., Langacker, R.W., Taylor, J.R. (ed.) Cognitive Approaches to Lexical Semantics. New York: Mouton de Gruyter.

Hansen, L. (2003). The Functions and Meanings of Word-formation (With reference to modern English). In: Hladky, J. Language and Function: To the Memory of Jan Firbas(pp.47-62). Amsterdam/Philadelphia: John Benjamins Publishing Company.

Hatcher, A. G. (1960). An Introduction to the Analysis of English Noun Compounds. [Online]. WORD. Available:https://www.tandfonline.com/doi/abs/10.1080/00437956.1960.11659738 
Kiefer, F. (1998). Morphology and Pragmatics. In: Spencer, A. \& Zwicky, A. (ed.).The Handbook of Morphology (pp.272-279). Oxford: Blackwell.

King, J.C. \& Stanley, J. (2005). Semantics, Pragmatics, and the Role of Semantic Content. In: Szabo, Z. G. (ed.) Semantics Versus Pragmatics(pp. 111-164).Oxford: Oxford University Press.

Lees, R. B. (1960). The Grammar of English Nominalizations. Bloomington, IN: Indiana University Press.

Meibauer, J. (2014). Word-Formation and Contextualism. International review of Pragmatics. No. 12, pp.103-126.

Meyer, R. (1993). Compound Comprehension in Isolation and in Context: The contribution of conceptual and discourse knowledge to the comprehension of German novel noun-noun compounds. Tübingen: Max Niemeyer Verlag.

Oxford Dictionary of New Words. (1990). Oxford: Oxford University Press.

Schmid, H. J. (2011). Conceptual blending, relevance and novel N+N-compounds. In: Schmid, H.J., Handl, S. (ed.) Cognitive Linguistics Research: Windows to the Mind: Metaphor, Metonymy and Conceptual Blending. Berlin: Walter de Gruyter.

Søgaard, A. (2005). Compounding Theories and Linguistic Diversity. In: Frajzyngier, Z., Hodges, A., Rood, D. S. (ed.) Linguistic Diversity and Language Theorie s(pp.319-338). Amsterdam/Philadelphia: John Benjamins Publishing Company.

Štekauer, P. (2005). Meaning Predictability in Word Formation: Novel, context-free naming units. Amsterdam/Philadelphia: John Benjamins Publishing Company.

Taylor, J. R. (2012). Contextual Salience, Domains, and Active Zones. In: Bublitz et el. (ed.) Cognitive Pragmatics(pp. 151-174).Berlin/Boston: De Gruyter Mouton.

Wilson, D. \&Sperber, D. (2002). Relevance Theory. In: Ward, G., Horn, L. (ed.) Handbook of Pragmatics. Malden, MA: Blackwell Publishing.

Wisniewski, E. (1997). When Concepts Combine. Psychonomic Bulletin \& Review, 1997, 4 (2), 167-183. 